\title{
A study to evaluate comparative efficacy of two different venous occlusion duration on pretreatment with Inj. lignocaine to prevent propofol Inj. pain in patients undergoing surgery under general anaesthesia
}

\author{
Atlanta Talukdar ${ }^{1}$, Sara Mary Thomas ${ }^{2, *}$, Akhilesh Chhaya ${ }^{3}$, Dinesh K Chauhan ${ }^{4}$ \\ ${ }^{1}$ PG Resident, ${ }^{2}$ Assistant Professor, ${ }^{3}$ Professor, ${ }^{4} \mathrm{Head}$ and Professor, Dept. of Anaesthesiology, SBKS Medical Institute and \\ Research Center, Vadodara, Gujarat, India
}

*Corresponding Author: Sara Mary Thomas

Email: sara.cinosh@gmail.com

Received: $4^{\text {th }}$ May, 2018

Accepted: $3^{\text {rd }}$ July, 2018

\begin{abstract}
Aim: To study the efficacy of two different time duration of venous occlusion in preventing propofol injection pain.

Materials and Methods: In this prospective, randomized controlled study patients of either gender, scheduled to undergo elective surgery under general anaesthesia were randomly assigned into 2 groups (Group L30 and Group L60) of 25 patients each. Group L30 and Group L60 received Injection (Inj) Lignocaine 40mg intravenously under venous occlusion for 30 seconds and 60 seconds respectively followed by Inj propofol for induction. propofol induced pain was assessed after administration of $25 \%$ of total calculated dose of propofol.

Results: In our study, significantly more patients in Group L30 (72\%) reported pain as compared to Group L60 (32\%). (p < $0.05)$.

Considering the severity of pain, in Group L30, out of $72 \%$ who had pain; $64 \%$ had mild pain and $8 \%$ had moderate pain. Whereas in Group L60, 32\% had pain and all had mild pain only.

Conclusion: The study found that pretreatment with Inj Lignocaine $40 \mathrm{mg}$ under venous occlusion for 60 seconds followed by Inj propofol for induction significantly reduced the incidence and the severity of pain of propofol injection when compared with the group who received $40 \mathrm{mg}$ of Inj. Lignocaine under venous occlusion for 30 seconds.
\end{abstract}

Keywords: Propofol injection, Pain, Local anesthetic, Lignocaine, Venous occlusion.

\section{Introduction}

Propofol is a rapidly acting intravenous anaesthetic agent, which is used widely as an induction agent for general anaesthesia due to its smooth induction and rapid recovery properties. However, propofol has its drawbacks as it has been reported to cause substantial pain on Injection (Inj). ${ }^{1}$ The incidence of the propofol injection pain varies between $28 \%$ and $85 \%{ }^{1}$

Several methods have been administered over the years to reduce the pain associated with Intravenous (IV) injection of propofol. ${ }^{1}$ These include: non-drug category, ${ }^{1}$ drug category and conjunction of the two. ${ }^{1}$

The non-drug category includes the studies that used mechanical incessions such as injection sites, ${ }^{2}$ needle sizes, ${ }^{3}$ temperature, ${ }^{4}$ venous occlusion, ${ }^{5}$ bacteriostatic, ${ }^{6}$ microfiltration. ${ }^{7}$ The most effective was the selection of an antecubital vein contrast to a hand vein as the injection site. ${ }^{8}$

The drug category constituted various drugs or drug combination for example.

Benzodiazepines, ${ }^{1} \quad$ Local Anaesthetics, ${ }^{9}$ Barbiturates ${ }^{10}$ and most of these drugs were partially productive in reducing the pain from propofol injection. A lidocaine - propofol admixture $(25 \text { trials })^{10}$ was found the most potent intervention. ${ }^{10}$ Ketorolac, ${ }^{11}$ Diclofenac, Ketamine, Flurbiprofen were the prime agents explored for potential reduction of pain from propofol injection.
The combined drug and non-drug category incorporated non-drug techniques such as venous occlusion, ${ }^{8}$ alteration of temperature ${ }^{4}$ of propofol ${ }^{4}$ and site of injection. ${ }^{2}$ The most commonly studied intervention was venous occlusion ${ }^{8}$ in conjunction with various drugs such as antiemetics, ${ }^{9}$ non-steroidal antiinflammatory drugs, ${ }^{12}$ ketamine, lidocaine, and Opioids ${ }^{13}$ for reducing the risk of pain from propofol injection.

In this category pretreatment using lidocaine ${ }^{14}$ combined with venous occlusion was found to be the most effective intervention at preventing the pain from propofol injection.

The duration of 60 seconds have been studied and is believed to allow enough time for the drug to act locally. ${ }^{4}$

Hence, we planned to do a comparative study of effect of different time duration of venous occlusion ${ }^{14}$ by applying a tourniquet for 30 seconds and 60 seconds $^{14}$ on pre treatment with Inj Lignocaine in prevention of propofol injection pain in patients undergoing surgeries under general anaesthesia.

\section{Materials and Methods}

After obtaining approval of the ethics committee and written informed consent from patients, ${ }^{14} 50$ American Society of Anaesthesiology (ASA) Grade I \& II patients of either gender, aged 18 to 55 years 
admitted to Dhiraj Hospital, S.B.K.S.M.I.R.C. Piparia, Vadodara, Gujarat, scheduled for surgeries, under general anaesthesia were subjected to study. Data was collected for six months and was analysed statistically.

Based on previous study in literature, the incidence of pain ${ }^{15}$ on injecting propofol was taken to be $80 \%$ and $50 \%$ reduction in pain was considered clinically significant. The minimum size for each group, assuming a value of 0.05 and a power value of $90 \%{ }^{16}$ was thus calculated to be twenty two. Patients was divided into two groups of 25 each. Statistical analysis was performed using a statistical software package (SPSS Inc., Chicago, IL) for windows version 10.0.

Patients willing to sign informed consent, aged 18 years to 55 years, undergoing elective surgeries under general anaesthesia and belonging to ASA Grade I and II were included in our study. ${ }^{14}$

Patients with poor cardiovascular and respiratory reserve, belonging to ASA Grade III or more, who previously had allergic reactions, sensitivity or any other form of reaction to the study drug, who have anticipated difficult airway (Mallampati grade $3 \& 4$ ) and who are taking sedatives or analgesics in the past 24 hours before surgery were excluded from the study. Patients having conditions where tourniquet application is contraindicated like- peripheral vascular disease, poor skin condition of the limb, peripheral neuropathy, arteriovenous (AV) fistula, severe infection of the limb, head injury or CNS disorder, severe arthritic changes or bony spurs or previous fracture of the limb, sickle cell haemoglobinopathy, severe trauma to the limb were excluded from our study. ${ }^{14}$

Detailed pre-anaesthetic check-up of the patients posted for elective surgery were done a day prior, to decide their eligibility to undergo the said study. They were assessed for height, weight and vitals namely pulse rate, blood pressure, respiratory rate and temperature were noted.

The patients were investigated for the following tests:

Complete blood count, random blood sugar, liver function test, renal function test, ECG, Chest x-ray PA view and other special investigations if required. Patients were kept nil by mouth for 6 hours preoperatively.

A 20 gauge venous cannula was introduced into a vein on the patient's dorsum side of the hand in the first attempt and a bivalve to facilitate injections ${ }^{14}$ was connected. Inside the operation theatre (OT), standard monitors (Pulse Rate, Blood Pressure, Oxygen Saturation and Electrocardiogram) were attached and baseline parameters were recorded..$^{14}$ All patients were pre-loaded with Ringer lactate $10 \mathrm{ml} / \mathrm{kg} \mathrm{IV}$ and were premedicated with Inj Glycopyrolate $0.004 \mathrm{mg} / \mathrm{kg}$ IV and Inj Ondansetron $0.08 \mathrm{mg} / \mathrm{kg}$ IV. Patients were randomly allocated, by the use of chit method, into two groups of 25 patients each.
1. Group L30 received $40 \mathrm{mg}$ of Inj Lignocaine in 5 $\mathrm{ml}$ saline under venous occlusion for 30 seconds followed by Inj propofol for induction

2. Group L60 received $40 \mathrm{mg}$ of Inj Lignocaine in 5 $\mathrm{ml}$ saline under venous occlusion for 60 seconds followed by Inj propofol for induction

Pre oxygenation was carried out with face mask of appropriate sized for 3 minutes with $100 \%$ oxygen followed by induction of anaesthesia. ${ }^{17}$

After applying venous occlusion with sphygmomanometer $\operatorname{cuff}^{18}$ as a tourniquet ${ }^{19}$ at a pressure of about $70 \mathrm{~mm}$ of $\mathrm{Hg}$, the assigned dose $^{20}$ of Lignocaine $40 \mathrm{mg}^{21}$ was injected IV. The tourniquet was released after 30 seconds $^{22}$ in L30 group and after 60 seconds $^{22}$ in L60 group. This was followed by administration of $25 \%$ of total calculated dose of Inj propofol over 10 seconds, after which crystalloids were delivered at maximal gravity flow. Before the administration of total allocated dose of Inj propofol, each patient had been asked to immediately rate any sensation of pain during the propofol injection according to the Pain score ${ }^{15}$ which was graded as follows:

1. No pain.

2. Mild pain (discomfort in the hand or arm which is acceptable to the patient).

3. Moderate pain (discomfort in hand or arm which is unacceptable).

4. Severe pain (grimace or limb withdrawal).

Heart rate and blood pressure were noted before pretreatment and before pretreatment and after pretreatment with Inj Lignocaine and at 0, 1, 2 and 3 minutes after propofol bolus. ${ }^{14}$ Change in heart rate of $+/$ - 20 beats/minute and $20 \%$ rise or fall in blood pressure from the baseline were considered clinically significant in the study.

\section{Statistical Analysis}

Data was collected, tabulated. Numerical variables was propounded as mean \&standard deviation (SD) while categorical variables was suggested as frequency and percentage. ${ }^{15}$ As regard numerical variables; unpaired student $-t$ test was used whenever appropriate, for between-groups comparisons, while for categorical variables; chi-square test was used. A difference with significant level $<0.05$ was considered statistically significant. Statistical analysis was performed using a statistical software package (SPSS Inc., Chicago, IL) for windows version 10.0 .

\section{Observation and Results}

Demographic datas were comparable in both the groups.

In group L30, $28 \%$ of patients (i.e 7 out of 25 ) experienced no pain whereas $72 \%$ of patients (i.e 18 out of 25) experieced pain as against group L60, in which $68 \%$ of patients (i.e 17 out of 25 ) encountered no pain 
whereas $32 \%$ of patients (i.e 8 out of 25 ) had pain as shown in Table 1 and Graph 1.This difference was statistically significant $(\mathrm{p}$ value $<0.05)$.

Table 1 Showing incidence of pain in patients receiving propofol injection (25 patients in each group) following inj. Lidocaine under venous occlusion

\begin{tabular}{|l|c|c|c|c|c|}
\hline \multirow{2}{*}{ Variable } & \multicolumn{2}{|l|}{ Group L30 } & \multicolumn{2}{|c|}{ Group L60 } & \multirow{2}{*}{ P - value } \\
\cline { 2 - 5 } & No. of patients & $\%$ & No. of patients & $\%$ & \\
\hline No. of patients with pain & 18 & 72 & 8 & 32 & \multirow{2}{*}{ (significant) } \\
\hline No. of patients without pain & 7 & 28 & 17 & 68 & 100 \\
\hline Total & 25 & 100 & 25 & \\
\hline
\end{tabular}

Considering severity of pain among $72 \%$ of patients in group L30, $64 \%$ of patients (i.e 16 out of 25 ) experienced mild pain and $8 \%$ of patients (i.e 2 out of 25) had moderate pain.
Amongst $32 \%$ of the patients in group L60 who had pain, all the patients had mild pain only. These results are depicted in Table 2 and Graph 2.

It was also observed that no patient in either group had severe pain.

Table 2: Comparison of groups according to pain score grading $[P<0.05]$

\begin{tabular}{|l|c|c|c|c|}
\hline \multirow{2}{*}{ Pain score grading } & \multicolumn{2}{|c|}{ Group L30 } & \multicolumn{2}{c|}{ Group L60 } \\
\cline { 2 - 5 } & No. of patients & \% & No. of patients & \% \\
\hline 0(no pain) & 7 & 28 & 17 & 68 \\
\hline 1(mild pain) & 16 & 64 & 8 & 32 \\
\hline 2(moderate pain) & 2 & 8 & 0 & 0 \\
\hline 3(severe pain) & 0 & 0 & 0 & 0 \\
\hline Total & 25 & 100 & 25 & 100 \\
\hline
\end{tabular}

$P$ value is $<0.05$ which is significant.

\section{Discussion}

In our study, in Group L30, $28 \%$ of patients had experienced no pain whereas $72 \%$ of patients had complained of pain as against Group L60, in which $68 \%$ of patients had experienced no pain whereas $32 \%$ of patients had complained pain. Considering severity of pain, amongst $72 \%$ of patients in group L30 who had experienced pain, $64 \%$ of patients had mild pain and $8 \%$ of patients had moderate pain.

Amongst $32 \%$ of the patients in group L60 who had experienced pain, all the patients i.e $32 \%$ of patients had sustained mild pain only. It was also observed that no patient in either group had severe pain.

These results helped us to decide the duration ${ }^{22}$ of venous occlusion ${ }^{8}$ that is to be kept before injecting Lignocaine for pretreatment, in clinical practice, to achieve adequate pain relief from propofol injection pain. ${ }^{1}$

Pain after propofol injection has been a common issue during induction of anaesthesia and can be distressing to the patient. ${ }^{17}$ The reported incidence of pain varies between $28 \%$ and $85 \%^{1}$ in adults during induction of anesthesia and may be severe. ${ }^{1}$ The cause of pain on propofol injection ${ }^{1}$ is not clear, although there are several proposed mechanisms. ${ }^{17}$ Stimulation of the nociceptive receptors at the free nerve endings located between the intima and the media layers of the venous wall, ${ }^{1}$ triggering of the kinin cascade, ${ }^{16}$ and the effect of propofol $\mathrm{pH}^{17}$ and concentration are all suggested possible mechanisms of propofol-induced pain. $^{17}$

Pre injected lignocaine is thought to act mostly as a local anesthetic. It has been proposed that Lignocaine is not effective in reducing the pain of propofol injection, except when combined with venous occlusion ${ }^{8}$ The reason for applying venous occlusion with lignocaine is because it allows enough time for blocking $\mathrm{A} \delta$ fibres as these are responsible for transmission of pain in the inner walls of the vessels. ${ }^{18}$

This mechanism of action is possibly due to the blockade of the nerve fibers responsible for pain transmission, ${ }^{1}$ resulting from direct irritation of the inner walls of blood vessels by propofol; ${ }^{1}$ this direct anesthetic effect of lidocaine ${ }^{8}$ is achieved when sufficient time is allowed for the drug to work. ${ }^{19}$

In our study, Inj Lignocaine under venous occlusion for 60 seconds $^{22}$ followed by Inj propofol for induction was associated with a greater reduction in propofol-induced pain as compared to the group which received Inj. Lignocaine under venous occlusion for 30 seconds. ${ }^{22}$ This difference in effect might have been due to the longer duration of venous occlusion ${ }^{23}$ with the local anaesthetic ${ }^{24}$ and hence giving sufficient time for its activity, resulting in greater reduction of pain during propofol injection.

\section{Conclusion}

The study found that pretreatment with $40 \mathrm{mg}$ of Inj. Lignocaine in $5 \mathrm{ml}$ saline under venous occlusion for 60 seconds followed by Inj propofol for induction, 
significantly reduced the incidence and the severity of pain during the injection of propofol when compared with the group who received $40 \mathrm{mg}$ of Inj Lignocaine in $5 \mathrm{ml}$ saline under venous occlusion for 30 seconds.

\section{Conflict of Interest: None}

\section{References}

1. Stark RD, Binks SM, Dutka VN, O'Connor KM, Arnstein MJA, Glen JB. A review of the safety and tolerance of propofol ('Diprivan'). Postgraduate Medical Journal. 1985;61(5):152-6.

2. Kobayashi Y, Tsuchida A, Kamada Y, Seki S, Ichimiya T, Namiki A. Effects of speed of injection on anesthesia induction with propofol and fentanyl. Masui. 1999;48:847-51.

3. Lomax D. Propofol injection pain. Anaesthesia and Intensive Care. 1994;22:500-14.

4. Fletcher GC. The effect of temperature upon pain during injection of propofol. Anaesthesia. 1996;51:498-9.

5. A Sunny, T Veerabhadraiah, S Trivikram. Comparison of Pretreatment With Lignocaine And Ondansetron For Pain On Injection of Propofol During Induction Of Anaesthesia. The Internet Journal of Anesthesiology. 2013;32:1..

6. Cho J, Cho JC, Lee P. Formulation and evaluation of an alternative triglyceride-free propofol microemulsion. Arch Pharm Res. 2010;33:1375-1387.

7. Davies AF, Vadodaria B, Hopwood B, Dexter T, Conn D. Efficacy of microfiltration in decreasing propofolinduced pain. Anaesthesia. 2002;57:557-61.

8. Picard P and Trame`r MR. Prevention of pain on injection with propofol: a quantitative systematic review. Anesth Analg. 2000;90:963-969.

9. A Sunny, T Veerabhadraiah, S Trivikram. Comparison of Pretreatment With Lignocaine And Ondansetron For Pain On Injection of Propofol During Induction Of Anaesthesia. The Internet Journal of Anesthesiology. 2013;32:1

10. P. LEE. A Comparison Between Lignocaine Pretreatment and Lignocaine Added to Propofol Anaesth Intensive Care 2004;32:482-484.

11. Huang YW, Buerkle H, Lee TH. Effect of pretreatment with ketorolac on propofol injection pain. Acta Anaesthesio/Scand. 2002;46:1021-1024.

12. Canbay O, Celebi N, Arun O. Efficacy of intravenous acetaminophen and lidocaine on propofol injection pain. Br J Anaesth. 2008;1000:95-98.

13. Rahman Al-Refai A, Al-Mujadi H, Petrova Ivanova M, Marzouk HM, Batra YK, Al-Qattan AR. Prevention of pain on injection of propofol: A comparison of remifentanil with alfentanil in children. Minerva Anestesiol. 2007;73:219-23.

14. Sedat Kaya. Lidocaine for Prevention of Propofol Injection-Induced Pain: A Prospective, Randomized, Double-Blind, Controlled Study of the Effect of Duration of Venous Occlusion with a Tourniquet in Adults. Current Therapeutic Research. 2008;69:I.

15. Tan CH, Onsiong MK, Kua SW. The effect of ketamine pretreatment on propofol injection pain in 100 women. Anaesthesia. 1998;53(3):302-05.

16. Sim JY, Lee SH, Park DY. Pain on injection with microemulsion propofol. Br J Clin Pharmacol. 2009;67:316-325.

17. Tan $\mathrm{CH}$, Onsiong MK. Pain on injection of propofol. Anaesthesia. 1998;53:468-76.

18. Dae Hee Kim. Intravenous lidocaine pretreatment with venous occlusion for reducing microemulsion propofol induced pain: Comparison of three doses of lidocaine. Journal of International Medical Research. 2014;42(2):368-375.

19. Batra YK, AlQattan AR, Marzouk HM, SmilkaM, Agzamov A. Ketamine pretreatment with venous occlusion attenuates pain on injection with propofol. Eur J Anaesthesiol. 2005;22:69-70.

20. Karasawa F, Ehata T, Okuda T, Satoh T. Propofol injection pain is not alleviated by pretreatment with flurbiprofen axetil, a prodrug of a nonsteroidal antiinflammatory drug. J Anesth. 2000;14(3):135-137.

21. Ashok Chaudhari and Devavrat Vaishnav. International Journal of Biomedical Research. 2016;7(3):118-121.

22. Islam M. Duration of venous occlusion with lidocaine for preventing propofol induced pain. Saudi Med J 2008;29(7):1-6.

23. Ewart MC. Prevention of pain during injection of propofol. Lancet. 1990;355:798-799.

24. Mc Culloch MJ. Assesment and modification of pain on induction with propofol. Anaesthesia. 1985;40:1117-20.

How to cite this article: Talukdar A, Thomas S. M, Chhaya A, Chauhan D. K. A study to evaluate comparative efficacy of two different venous occlusion duration on pretreatment with Inj. lignocaine to prevent propofol Inj. pain in patients undergoing surgery under general anaesthesia. Indian $\mathbf{J}$ Clin Anaesth. 2018;5(4):461-464. 